\title{
Assessment of Serum Lipid and Uric Acid Levels in Women with Normal Pregnancy and Pre-Eclampsia
}

\author{
Beenish Ghaffar, Shahida Hassan Memon, Feriha Fatima Khidri
}

\begin{abstract}
OBJECTIVES: To determine and compare the serum lipid profile and uric acid concentration in pre-eclamptic and normal pregnant women.

METHODOLOGY: This cross sectional study was carried out at Biochemistry Department, LUMHS Jamshoro with the collaboration of Gynaecology and Obstetrics Department and Diagnostic \& Research Laboratory, Pathology Department, LUMHS Jamshoro from March 2016 to December 2016. Patients were selected via non-probability consecutive sampling. A total of 60 subjects were enrolled and divided into two groups comprising women with normal pregnancy $(n=30)$ as controls and women with pre-eclampsia $(n=30)$ as cases after applying exclusion criteria.

RESULTS: Mean age of women with pre-eclampsia and normal pregnancy was found to be $26.77 \pm 2.58$ and 26.30 \pm 2.05 years $(p$-value=0.44). Significantly higher levels $(p$-value $<0.05)$ of triglycerides $(T G)$, total cholesterol (TC), low density lipoproteins (LDL) and serum uric acid were found in the women with pre-eclampsia as compared to controls; whereas, high density lipoproteins (HDL) were significantly lowered $(p$-value $<0.05)$ in women with pre-eclampsia. Uni-variate analysis showed that the TG $(O R=7.67), T C(O R=3$ and 5.55), $L D L(O R=3.59)$ and uric acid $(O R=11.23)$ were significantly increased and HDL $(O R=9.75)$ were significantly lowered in women with pre-eclampsia than in women with normal pregnancy $(p$-value $<0.05)$. In the multi-variate logistic model, TG $(O R=4.28)$ and uric acid $(O R=6.62)$ were significantly increased and HDL $(O R=4.31)$ were significantly lowered in women with pre-eclampsia than in women with normal pregnancy $(p$-value $<0.05)$

CONCLUSION: Alteration in the serum uric acid and TG concentration may be helpful in early detection and monitoring of pre-eclampsia cases. This information may be utilized in preventing the adverse outcomes occurring as a result of pre-eclampsia.
\end{abstract}

KEYWORDS: Lipid, Pre-eclampsia, Pregnancy, Uric acid

This article may be cited as: Ghaffar B, Memon SH, Khidri FF. Assessment of Serum Lipid and Uric Acid Levels in Women with Normal Pregnancy and Pre-Eclampsia. J Liaquat Uni Med Health Sci. 2019;18(02):169-74. doi: 10.22442/jlumhs.191820622

\section{INTRODUCTION}

Pre-eclampsia is mainly characterized as the hypertensive disorder of pregnancy, which is responsible for feto-maternal complications resulting in death, especially in low socioeconomic populations ${ }^{1,2}$. Pre-eclampsia has various systemic manifestations such as raised blood pressure of $140 / 90 \mathrm{mmHg}$ or more after $20^{\text {th }}$ weeks of pregnancy with proteinuria of the $\geq 300 \mathrm{mg} / \mathrm{day}^{3}$. It tends to occur later in pregnancy, but rapidly evolves to severe disease requiring emergency caesarean section. It enhances the risks in the fetus for intrauterine growth restriction (IUGR), low birth weight and prematurity, which later on can predispose neonates to diabetes mellitus, hypertension and vascular disorders ${ }^{4}$.

Various studies suggest abnormal placentation as the main reason behind the disorder ${ }^{5}$. Numbers of mechanisms have been proposed for the development of pre-eclampsia; though, endothelial dysfunction leading to the oxidative stress and contributing to the altered lipid profile in women with pre-eclampsia have been considered as a significant risk factor in previous studies ${ }^{6}$. It has been suggested that dyslipidemia in the beginning of pregnancy has high risks of pre-eclampsia and eclampsia ${ }^{7}$.

Increased serum or plasma triglyceride (TG) concentration greater than $1.6 \mathrm{mmol} / \mathrm{l}$ is referred as hypertriglyceridemia. Though various studies have elucidated the association of maternal obesity, chronic hypertension and diabetes mellitus with pre-eclampsia ${ }^{8}$, limited data is available about the association between hypertriglyceridemia and pre-eclampsia. Previously, various studies have noted abnormal levels of total cholesterol (TC), TG, low-density lipoprotein (LDL) and high-density lipoprotein (HDL) in pre-eclampsia ${ }^{9}$. Lower levels of HDL have been proposed as a predictor for the severity of pre-eclampsia as well as indicator of poor prognosis for pre-eclampsia ${ }^{10}$. It is postulated that increase 
levels of estrogen and progesterone in pre-eclampsia elevates the levels of LDL, which inhibits vasodilation and result in endothelial dysfunction which ultimately leads to proteinuria. Functions of HDL in transporting excessive cholesterol from peripheral tissues to liver and activating lipoprotein lipase are well known; which are compromised due to its lower levels. In addition to that, an increase in level of cholesterol generates free radicals potentially relating athrogenic effect on pre-eclampsia ${ }^{11}$.

Further, extensive cellular activity associated with placental ischemia leads to increased production of uric acid, serving as a marker of disease. Uric acid is end product of purine catabolism and its elevated level initiates endothelial dysfunction, which may provoke hypertension and vascular disorders ${ }^{12}$. Although investigation of lipid parameters in relation with pre-eclampsia have been studied in western countries however, limited data is available in population of Sindh, Pakistan.

The objectives of the current study were: (i) To determine serum lipid profile and uric acid levels in women with pre-eclampsia and normal pregnancy (ii) To compare the maternal serum lipid profile and uric acid concentration between women with healthy pregnancy and pre-eclampsia.

\section{METHODOLOGY}

This cross sectional study was conducted in the Department of Biochemistry, Liaquat University of Medical and Health Sciences, Jamshoro with the collaboration of Department of Gynaecology/ Obstetrics and Diagnostic \& Research Laboratory, Pathology Department, from March 2016 to December 2016. The sample size was calculated by using OpenEpi, Open source statistics for public health software by taking prevalence of pre-eclampsia as $1.9 \%$ from previous study conducted in Pakistan ${ }^{13}$, with a proportion of $95 \%$ confidence interval $(\mathrm{Cl})$ and a $5 \%$ margin of error. The calculated sample size was 60 . Total 60 women were enrolled and divided into two groups; Group I: Comprised of 30 women with normal pregnancy and Group II: Comprised of 30 women with pre-eclampsia. The non-probability consecutive sampling was used as sampling technique. The inclusion criteria for group I were pregnant women with normal blood pressure, age range between 18-30 years and 28-38 weeks of gestational age receiving antepartum care; whereas, for group II women with diagnosed pre-eclampsia with age range between 18-30 years and 28-38 weeks of gestational age. Women with pre-eclampsia having pre-existing hypertension, ischemic heart disease, chronic renal failure, liver diseases, diabetes mellitus, taking drugs that alter lipid profile, thyrotoxicosis, multiple gestation, twin pregnancy, severe anemia, gout, smoking, alcohol abuse and tobacco abuse were excluded. Pre-eclampsia for the present study was defined as blood pressure $\geq 140 / 90 \mathrm{mmHg}$ taken on two readings 6 hours apart and proteinuria $\left(\geq 0.3 \mathrm{~g} / 24 \mathrm{~h}\right.$, or $\geq 1+$ by dipstick) after completing $20^{\text {th }}$ weeks of pregnancy in a previously normotensive woman $^{14}$. Categories of lipid profile parameters were made according to the guidelines of the American association of clinical endocrinologists; Table $1^{15}$.

\section{TABLE I: DIAGNOSTIC CRITERIA OF LIPID PROFILE IN SERUM ACCORDING TO AMERICAN ASSOCIATION OF CLINICAL ENDOCRINOLOGISTS}

\begin{tabular}{|l|c|c|c|}
\hline & $\begin{array}{c}\text { Optimal/near } \\
\text {-optimal }\end{array}$ & Borderline & $\begin{array}{c}\text { High-risk/very } \\
\text { high-risk }\end{array}$ \\
\hline TG & $<150$ & $150-199$ & $\begin{array}{c}200-499 \text { gh; } \geq 500 \\
\text { very high }\end{array}$ \\
\hline TC & $<200$ & $200-239$ & $\geq 240$ \\
\hline HDL-C & $\geq 60$ & $50-59$ & $<50$ \\
\hline LDL-C & $<100-129$ & $130-159$ & $\begin{array}{c}160-189 \text { high; } \geq \\
190 \text { very high }\end{array}$ \\
\hline
\end{tabular}

The abnormal uric acid level was defined as value $>5$ $\mathrm{mg} / \mathrm{dl}$ as a strong indicator of disease ${ }^{16}$.

The blood samples were collected from the pre-eclamptic and normal pregnant women of the same age, gestational age, and body mass index (BMI). Mercury sphygmomanometer was used for recording the blood pressure in the right arm during rest and sitting position. Three readings were taken and mean of the 3 were recorded. Under aseptic measures blood samples were collected and labelled for identification. Four $(04) \mathrm{ml}$ of venous blood was collected in the serum separator tube (vacutainer). Samples were left to stand upright at $37 \mathrm{C}^{\circ}$ for 30 minutes for clotting; later centrifuged for about 15 minutes at 3000 rotations per minute (rpm) to separate serum from clot. The investigations were performed in Research \& Diagnostic Laboratory of Pathology Department, LUMHS Jamshoro. Lipid profile and uric acid were determined by spectrophotometry (Merck Microlab 300).

Statistical Package for Social Science (SPSS) software version 19 was used for the analysis of data. Categorical variables expressed as frequency/ percentage were analysed by chi-square test; whereas, for the continuous variables, mean and standard deviation were calculated. The independent sample t-test was applied to compare mean concentrations between women with pre-eclampsia and normal pregnancy. $\mathrm{P} \leq 0.05$ was considered as level of significance. According to the cut-off value of serum variables, uni-variate logistic regression was 
performed and un-adjusted odds ratio was computed for each predictor.

\section{RESULTS}

In our study, mean age of women with pre-eclampsia was $26.77 \pm 2.58$ years and of controls was $26.30 \pm 2.05$ years $\quad(p$-value $=0.44) \quad($ Figure $\quad \mathrm{I})$. There were statistically significant differences $(p$-value $<0.0001)$ in mean systolic and diastolic blood pressures between women with pre-eclampsia and normal pregnancy.

Significantly increased levels of TG, TC, LDL and uric acid and decreased HDL were observed in women with pre-eclampsia against women with normal pregnancy $(p$-value $<0.05)$ (Table II).

In uni-variate analysis unadjusted odds ratio showed that the TG[OR $(95 \% \mathrm{Cl}): 7.67(2.42-24.24)]$, TC[OR $(95 \% \mathrm{Cl}): 3$ (0.83-10.81) and 5.55(1.39-21.71)], LDL [OR $(95 \% \mathrm{Cl}): 3.59(1.22-10.64)]$ and uric acid [OR $(95 \% \mathrm{Cl}): 11.23$ (3.09-40.71)] were significantly increased and HDL[OR (95\%Cl):9.75 (2.71-35.11)] were significantly lowered in women with pre-eclampsia than in women with normal pregnancy ( $p$-value $<0.05)$. In the multi-variate logistic model, TG [OR $(95 \% \mathrm{Cl}): 4.28(1.11-16.51)$ ] and uric acid [OR $(95 \% \mathrm{Cl}): 6.62 \quad(1.56-28.02)]$ were significantly increased and HDL [OR $(95 \% \mathrm{Cl}): 4.31$ (1.01-18.45)] were significantly lowered in women with pre-eclampsia than in women with normal pregnancy $(p$-value < 0.05) (Table IV).

\section{FIGURE I: AGE DISTRIBUTION OF WOMEN WITH} PRE-ECLAMPSIA AND NORMAL PREGNANCY

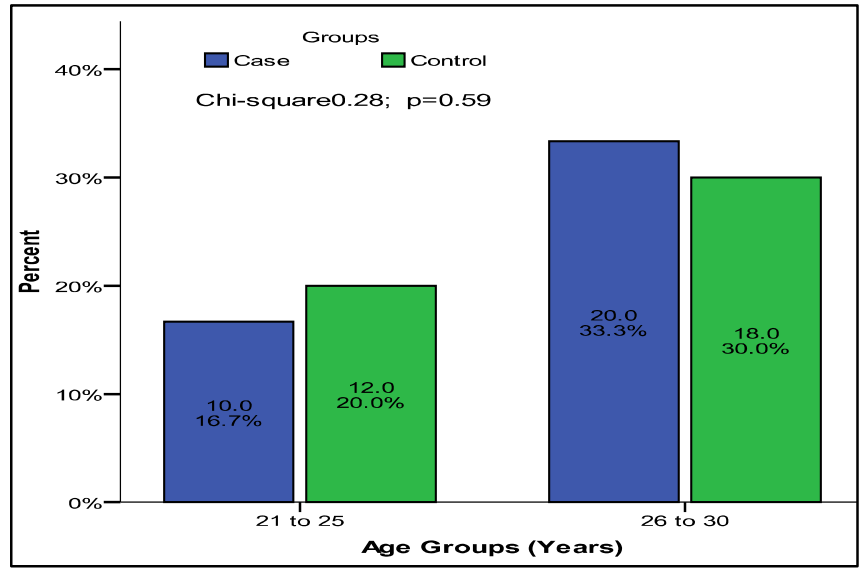

\section{DISCUSSION}

Pre-eclampsia is considered as third main reason of maternal deaths complicating $5-7 \%$ of pregnancies ${ }^{17}$. In this study, the average age of the women with pre-eclampsia and normal pregnancy was comparable. In the study conducted by Khurshid R $2016^{18}$, mean age of the women with pre-eclampsia and normal pregnancy were in similar range as found
TABLE II: COMPARISON OF VARIABLES BETWEEN WOMEN WITH PRE-ECLAMPSIA AND NORMAL PREGNANCY

\begin{tabular}{|l|r|r|r|}
\hline Variables & \multicolumn{1}{|c|}{$\begin{array}{c}\text { Women with } \\
\text { pre-eclampsia } \\
(\boldsymbol{n}=30)\end{array}$} & $\begin{array}{c}\text { Controls } \\
(\boldsymbol{n}=\mathbf{3 0})\end{array}$ & $\boldsymbol{p}$-value \\
\hline Age (Years) & $26.77 \pm 2.58$ & $26.30 \pm 2.05$ & 0.44 \\
\hline $\begin{array}{l}\text { Systolic BP } \\
(\mathrm{mmHg})\end{array}$ & $143.67 \pm 12.79$ & $125.8 \pm 6.45$ & $<0.0001$ \\
\hline $\begin{array}{l}\text { Diastolic BP } \\
(\mathrm{mmHg})\end{array}$ & $95.17 \pm 8.35$ & $83.47 \pm 4.89$ & $<0.0001$ \\
\hline TG & $222.47 \pm 91.23$ & $147 \pm 73.44$ & $<0.001$ \\
\hline TC & $222.1 \pm 51.25$ & $179.1 \pm 46.38$ & 0.0012 \\
\hline HDL & $117.70 \pm 32.7$ & $100.4 \pm 31.86$ & 0.042 \\
\hline LDL & $7.35 \pm 1.85$ & $4.92 \pm 1.28$ & $<0.0001$ \\
\hline Uric acid & & $52.97 \pm 6.56$ & $<0.001$ \\
\hline
\end{tabular}

The results are expressed as mean \pm standard deviation. Independent sample t-test applied for mean comparison.

TABLE III: THE COMPARISON OF LIPID PROFILE AND URIC ACID LEVELS BETWEEN WOMEN WITH PRE-ECLAMPSIA AND NORMAL PREGNANCY

\begin{tabular}{|l|r|r|l|}
\hline \multicolumn{1}{|c|}{ Variables } & $\begin{array}{r}\text { Women with } \\
\text { pre-eclampsia }\end{array}$ & Controls & p-value \\
\hline $\begin{array}{l}\text { TG(mg/dl) } \\
<150 \\
\geq 150\end{array}$ & $\begin{array}{r}9(30 \%) \\
21(70 \%)\end{array}$ & $\begin{array}{r}23(76.7 \%) \\
7(23.3 \%)\end{array}$ & 0.0005 \\
\hline $\begin{array}{l}\text { TC (mg/dl) } \\
<200 \\
200 \text { to 239 }\end{array}$ & $\begin{array}{r}10(33.3 \%) \\
9(30 \%)\end{array}$ & $\begin{array}{r}20(66.7 \%) \\
6(20 \%)\end{array}$ & 0.027 \\
$\geq 240$ & $11(36.7 \%)$ & $4(13.3 \%)$ & \\
\hline $\begin{array}{l}\text { HDL (mg/dl) } \\
<50 \\
50-59\end{array}$ & $18(60 \%)$ & $4(13.3 \%)$ & 0.0005 \\
\hline $\begin{array}{l}\text { LDL (mg/dl) } \\
\leq 129\end{array}$ & $12(40 \%)$ & $26(86.7 \%)$ & \\
$130-159$ & $13(43.3 \%)$ & $22(73.3 \%)$ & 0.018 \\
\hline $\begin{array}{l}\text { Uric acid (mg/dl) } \\
\leq 5\end{array}$ & $17(56.7 \%)$ & $8(26.7 \%)$ & \\
\hline 5 & $4(13.3 \%)$ & $19(63.3 \%)$ & 0.0002 \\
\hline $\begin{array}{l}\text { Results are presented as } n(\%) . \\
\text { applied Chi-square test }\end{array}$ \\
\hline
\end{tabular}

in our study. Another study supported the findings showing increase prevalence of pre-eclampsia in age group between 20-34 years ${ }^{19}$.

Increased levels of TG have been associated with increased risk of pre-eclampsia ${ }^{20}$. In present study TG 
Assessment of Serum Lipid and Uric Acid Levels in Women

TABLE IV: COMPARISON OF LIPID PROFILE AND URIC ACID LEVELS BETWEEN WOMEN WITH PRE-ECLAMPSIA AND NORMAL PREGNANCY BY UNIVARIATE AND MULTIVARIATE ANALYSIS MODEL

\begin{tabular}{|c|c|c|c|c|}
\hline \multirow[b]{2}{*}{ Variables $(\mathrm{mg} / \mathrm{dl})$} & \multicolumn{2}{|c|}{ Univariate } & \multicolumn{2}{|c|}{ Multivariate } \\
\hline & $p$-value & $\begin{array}{l}\text { Unadjusted } \\
\text { OR[95\% } 1 \text { CI] }\end{array}$ & $p$-value & $\begin{array}{l}\text { Adjusted } \\
\text { OR [95\%Cl] }\end{array}$ \\
\hline $\begin{array}{l}\text { TG } \\
<150 \\
\geq 150\end{array}$ & $0 . \overline{0005}$ & $\begin{array}{c}\text { Ref. } \\
7.67[2.42-24.24]\end{array}$ & 0.035 & $4.28[1.11-16.51]$ \\
\hline $\begin{array}{l}\text { TC } \\
<200 \\
200 \text { to } 239 \\
\geq 240\end{array}$ & $\begin{array}{l}\overline{-} \\
0.093 \\
0.015\end{array}$ & $\begin{array}{c}\text { Ref. } \\
3[0.83-10.81] \\
5.55[1.39-21.71]\end{array}$ & - & - \\
\hline $\begin{array}{l}\text { HDL } \\
<50 \\
50-59\end{array}$ & $\begin{array}{c}0.0005 \\
-\end{array}$ & $\begin{array}{c}\text { 9.75[2.71-35.11] } \\
\text { Ref. }\end{array}$ & 0.049 & $4.31[1.01-18.45]$ \\
\hline $\begin{array}{l}\text { LDL } \\
\leq 129 \\
130-159\end{array}$ & $\overline{0.018}$ & $\begin{array}{c}\text { Ref. } \\
3.59[1.22-10.64]\end{array}$ & - & - \\
\hline $\begin{array}{l}\text { Uric acid } \\
\leq 5 \\
>5\end{array}$ & $0 . \overline{0002}$ & $\begin{array}{c}\text { Ref } \\
11.23[3.09-40.71]\end{array}$ & 0.01 & $6.62[1.56-28.02]$ \\
\hline
\end{tabular}

$(\geq 150)$ levels were more than 4 times higher in women with pre-eclampsia than in women with normal pregnancy. It has been found that during normal pregnancy changes in the lipid metabolism occur, with the increase in concentration of lipids especially with the advancement of gestational age. Although, raised levels of TG and other lipids are found in pregnancy; nonetheless, TG increase disproportionately reaching two to four fold pre-pregnancy levels by the last trimester. These levels decrease after the delivery to pre-pregnancy levels ${ }^{21}$.

Hypertriglyceridemia result in an oxidative environment leading to endothelial injury predisposing to pre-eclampsia. Furthermore, it may predispose the baby born from mother suffering from pre-eclampsia to metabolic and cardiovascular disorders in adulthood $^{22}$. A study conducted in Egypt on cohort of $n=251$ pregnant women demonstrated the TG levels as predictor of pre-eclampsia between 4-12 weeks of pregnancy. This study further showed an increase in TG greater than $149.5 \mathrm{mg} / \mathrm{dl}$ as a cut-off point with positive predictive value and related increase in TG levels with severity 9 . A case control study conducted on Bangladeshi women detected significantly elevated serum TG concentration in women with pre-eclampsia $(242.9 \pm 36.8 \mathrm{mg} / \mathrm{dl})$ as compared to control group $(184.6 \pm 12.5 \mathrm{mg} / \mathrm{dl})$. The researchers concluded that increased levels of serum TG were positively correlated with blood pressure and proteinuria, demonstrating its association with the severity of the disorder $^{23}$. The results from these studies are in agreement with our findings. In our study, TG concentration in women with pre-eclampsia $(222.47 \pm 91.23 \mathrm{mg} / \mathrm{dl})$ were significantly ( $p$-value $<0.001)$ higher as compared to women with normal pregnancy $(147 \pm 73.44 \mathrm{mg} / \mathrm{dl})$.

Another study conducted by Wang $Y 2018^{24}$. found increased concentrations of TC, TG, and LDL in the serum of the women with pre-eclampsia as compared to the controls; further, concentrations showed rise in the levels with the progression or severity of the disorder. In addition, women with pre-eclampsia showed significantly decreased concentration of HDL in their study. Study conducted on Chinese women revealed decreased HDL during pregnancy was significantly associated with increased risk of gestational diabetes mellitus and macrosomic babies; whereas high HDL showed protective role against both factors ${ }^{25}$. These findings along with the results of our study suggested increased concentrations of TC, TG, and LDL and significantly decreased concentration of HDL in women with preeclampsia as compared to normal pregnancy. The current results are in agreement with various other studies that reported similar trend ${ }^{3,6,9}$.

Hyperuricemia occurs as a consequence of reduced 
renal excretion and increased formation of soluble uric acid due to oxidative stress and tissue ischemia in pre -eclampsia. Various studies have proposed uric acid role in causing hypertension, consequently due to endothelial dysfunction caused by its increased levels. During normal pregnancy alteration in the glomerular filtration rate (GFR) and effective renal plasma flow (ERPF) occurs, whereas in maternal hypertensive disorders vasospastic involvement of the kidney and placenta cause further damage to renal tubules and glomeruli. Increased uric acid levels may result in inhibition of fetal angiogenesis leading to further complications ${ }^{26}$.

A study conducted by Niraula A $2017^{27}$, found increased mean uric acid levels in gestational hypertension as compared to control group. In another study, uric acid concentrations in second trimester were observed as a good predictor for the pre-eclampsia at a cut-off value of $7.35 \mathrm{mg} / \mathrm{dl}^{28}$, which are consisted with our findings that found mean concentration of serum uric acid to be $7.35 \pm 1.85 \mathrm{mg} /$ dl. Corominas Al 2014 ${ }^{29}$, found no difference in the uric acid concentration in the first half of pregnancy in both normal pregnant and women with pre-eclampsia. However, after the $20^{\text {th }}$ week of gestation, serum uric acid increased to 1.5-fold in women with pre-eclampsia. It was also observed that increased levels of uric acid were correlated with low birth weight.

\section{CONCLUSION}

The alteration in the levels of lipid profile parameters and uric acid in pre-eclampsia suggests an early monitoring of these markers in pregnant women in order to avoid the adverse outcome of this disorder.

\section{RECOMMENDATIONS}

We recommend that further studies with larger sample size should be conducted to confirm the role of lipid parameters in the progression and severity of pre-eclampsia.

\section{ACKNOWLEDGMENT}

Authors would like to thank Dr.KhalidaNaz, chairperson community medicine department, LUMHS for providing assistance in statistical analysis of the study.

Ethical Permission: Liaquat University of Medical \& Health Sciences Reference No. LUMHS/REC/-49. Dated 07-03-2016.

Conflict of Interest: The authors declare no conflict of interest.

Funding: The present research did not receive any funding.

\section{REFERENCES}

1. Das B, Samanta S, Chaudhuri S. Assessment of serum magnesium and uric acid levels in women with normal pregnancy and pre-eclampsia in Rohilkhand region in Uttar Pradesh, India. Int J Health Sci Res. 2014; 4(1): 35-42.

2. Magnussen EB, Vatten LJ, Lund-Nilsen TI, Salvesen KA, Smith GD, Romundstad PR. Prepregnancy cardiovascular risk factors as predictors of pre-eclampsia: population based cohort study. Br Med J. 2007; 335(7627):978. doi: https:// doi.org/ 10.1136/bmj.39366.416817.

3. Serrano NC, Guio-Mahecha E, Quintero-Lesmes DC, Becerra- Bayona S, Paez MC, Beltran M, et al. Lipid profile, plasma apolipoproteins, and pre-eclampsia risk in the GenPE (International study of genetics and Preeclampsia) case-control study. Atherosclerosis. 2018; 276: 189-94.

4. Backes $\mathrm{CH}$, Markham $\mathrm{K}$, Moorehead $\mathrm{P}$, Cordero L, Nankervis CA, Giannone PJ. Maternal preeclampsia and neonatal outcomes. J Pregnancy. 2011; Article ID 214365: 7.

5. Fisher SJ. Why is placentation abnormal in preeclampsia? Am J Obstet Gynecol. 2015; 213(4 Suppl): S115-S122.

6. Timalsina S, Gyawali P, Bhattarai A. Comparison of lipid profile parameters and oxidized lowdensity lipoprotein between normal and preeclamptic pregnancies in a tertiary care hospital in Nepal. Int J Womens Health. 2016; 8: 627-31.

7. Mittal M, Kulkarni C, Panchonia A, Mittal R. Evaluation of serum lipid profile in cases of pre-eclampsia and eclampsia. Int $\mathrm{J}$ Reprod Contracept Obstet Gynecol. 2017; 3(3): 732-4.

8. Ray J, Diamond P, Singh G, Bell C. Brief overview of maternal triglycerides as a risk factor for pre-eclampsia. BJOG. 2006; 113(4): 379-86.

9. El Khouly NI, Sanad ZF, Saleh SA, Shabana AA, Elhalaby AF, Badr EE. Value of first-trimester serum lipid profile in early prediction of preeclampsia and its severity: A prospective cohort study. Hypertens Pregnancy. 2016; 35(1): 73-81.

10. Can E, Can MM, Tanboğa IH, Api O, Biteker M, Ünal O. High-density lipoprotein cholosterol may discriminate mild and severe preeclampsia. Gynecol Obstet Reprod Med. 2011; 17(2): 79-82.

11. Somani SG, Somani SR, Choudhary V, Babu PS, Vijayalaxmi A. To determine association of lipid profile, serum uric acid and body mass index as a marker for preeclampsia. Int J Cur Res Rev. 2015; 7(11): 53-7.

12. Johnson RJ, Kang D-H, Feig D, Kivlighn S, Kanellis $\mathrm{J}$, Watanabe $\mathrm{S}$, et al. Is there a 
pathogenetic role for uric acid in hypertension and cardiovascular and renal disease? Hypertension. 2003; 41(6): 1183-90.

13. Saeed F, Jawad A, Azmat A, Syed IA, Kagazwala S. Anthropometric measurements as a risk for hypertensive disorders in pregnancy: a hospital based study in South Asian population. J Pak Med Assoc.2011; 61(1): 58-63.

14. [No Authors Listed] Report of the national high blood pressure education program working group on high blood pressure in pregnancy. Am $\mathrm{J}$ Obstet Gynecol. 2000;183(1):S1-S22.

15. Jellinger $P S$, Handelsman $Y$, Rosenblit $P D$, Bloomgarden ZT, Fonseca VA, Garber AJ, et al. American association of clinical endocrinologists and American college of endocrinology guidelines for management of dyslipidemia and prevention of cardiovascular disease. Endocr Pract. 2017; 23 (s2): 1-87.

16. Lim K-H, Friedman SA, Ecker JL, Kao L, Kilpatrick SJ. The clinical utility of serum uric acid measurements in hypertensive diseases of pregnancy. Am J Obstet Gynecol. 1998; 178(5): 1067-71.

17. Vafaei $H$, Dalili $M$, Hashemi SA. Serum concentration of calcium, magnesium and zinc in normotensive versus preeclampsia pregnant women: A descriptive study in women of Kerman province of Iran. Iran J Reprod Med. 2015; 13(1): 23-6.

18. Khurshid R, Shamsi A, Fayyaz I, Zia M. Maternal serum uric acid level during pregnancy: A Biomarker for Preeclampsia. Pak J Med Health Sci. 2016; 10(2): 413-6.

19. Demirci O, Yılmaz E, Tosun Ö, Kumru P, Arınkan A, Mahmutoğlu D, et al. Effect of young maternal age on obstetric and perinatal outcomes: results from the tertiary center in Turkey. Balkan Med J. 2016;33(3):344-9. doi: 10.5152/balkanmedj.2015. 150364.

20. Contini C, Jansen M, König B, Markfeld-Erol F, Kunze $M$, Zschiedrich $S$, et al. Lipoprotein turnover and possible remnant accumulation in preeclampsia: insights from the Freiburg Preeclampsia H.E.L.P.-apheresis study. Lipids
Health Dis. 2018; 17(1): 49. doi:https:// doi.org/10.1186/s12944-018-0698-4

21. Mukherjee M. Dyslipidemia in Pregnancy. Am Coll Cardiol. [Published online] May 19, 2014. Available from: https://www.acc.org/latest-incardiology/articles/2014/ 07/18/16/08/ dyslipidemia-in-pregnancy.

22. Cortés-Vásquez J, Noreña I, Mockus I. Hypertriglyceridemia and adverse outcomes during pregnancy. Revista de la Facultad de Medicina. 2018; 66: 247-53. doi:10.15446/ revfacmed.v66n2.60791.

23. Manna F, Khanam N, Chowdhury K, Das S, Kabir $M$, Zubyra $S$, et al. Study on association of maternal serum triglyceride with pre-eclampsia. Mymensingh Med J. 2015; 24(3): 578-84.

24. Wang Y, Shi D, Chen L. Lipid profile and cytokines in hypertension of pregnancy: A comparison of preeclampsia therapies. J Clin Hypertens. 2018; 20: 394-9.

25. Jin WY, Lin SL, Hou RL, Chen XY, Han T, Jin Y, et al. Associations between maternal lipid profile and pregnancy complications and perinatal outcomes: a population-based study from China. BMC Pregnancy Childbirth. 2016; 16(1): 60. doi: 10.1186/s12884-016-0852-9.

26. Shouri R, Munagavalasa S, Vaitla P. Serum uric acid, serum iron levels in normal pregnancy and preeclampsia patients. Med Pulse Int J Biochem. 2018; 5(3): 97-9.

27. Niraula A, Lamsal M, Majhi S, Khan SA, Basnet P. Significance of serum uric acid in pregnancy induced hypertension. J Natl Med Assoc. 2017; 109(3): 198-202.

28. Rezk M, Gaber W, Shaheen A, Nofal A, Emara M, Gamal $A$, et al. First versus second trimester mean platelet volume and uric acid for prediction of preeclampsia in women at moderate and low risk. Hypertens Pregnancy. 2018; 37(3): 111-7.

29. Corominas Al, Balconi SM, Palermo M, Maskin B, Damiano AE. Serum uric acid levels and risk of developing preeclampsia. Medicina. 2014;74 (6):462-71.

\begin{tabular}{|ll|}
\hline AUTHOR AFFILIATION: & \\
$\begin{array}{l}\text { Dr. Beenish Ghaffar (Corresponding Author) } \\
\text { Lecturer, Department of Biochemistry }\end{array}$ & $\begin{array}{l}\text { Dr. Shahida Hassan Memon } \\
\text { Professor, Department of Biochemistry } \\
\text { Liaquat University of Medical and Health Sciences } \\
\text { (LUMHS), Jamshoro, Sindh-Pakistan. }\end{array}$ \\
$\begin{array}{ll}\text { Email: beenishghafar@gmail.com } & \text { Dr. Feriha Fatima Khidri } \\
& \text { Lecturer, Department of Biochemistry } \\
& \text { LUMHS, Jamshoro, Sindh-Pakistan. }\end{array}$ \\
\hline
\end{tabular}

